\title{
Impact of gender on chronic obstructive pulmonary disease outcomes: a propensity score- matched analysis of a prospective cohort study
}

Jaeyoung Cho ${ }^{1}$, Chang-Hoon Lee ${ }^{1}$, Deog Kyeom Kim ${ }^{2}$, Hun-Gyu Hwang ${ }^{3}$, Yu-Il Kim ${ }^{4}$, Hye Sook Choi ${ }^{5}$, Jeong-Woong Park ${ }^{6}$, Kwang Ha Yoo ${ }^{7}$, Ki-Suck Jung ${ }^{8}$, Sang-Do Lee ${ }^{9}$, and on behalf of the KOLD and KOCOSS Investigators

\begin{abstract}
${ }^{1}$ Division of Pulmonary and Critical Care Medicine, Department of Internal Medicine, Seoul National University Hospital, Seoul; ${ }^{2}$ Division of Pulmonary and Critical Care Medicine, Department of Internal Medicine, Seoul Metropolitan Government Seoul National University Boramae Medical Center, Seoul; ${ }^{3}$ Division of Respiratory, Department of Internal Medicine, Soonchunhyang University Gumi Hospital, Gumi; ${ }^{4}$ Department of Internal Medicine, Chonnam National University Hospital, Gwangju; ${ }^{5}$ Division of Pulmonary, Allergy and Critical Care Medicine, Department of Internal Medicine, Hallym University Kangdong Sacred Heart Hospital, Seoul; ${ }^{6}$ Division of Pulmonology, Department of Internal Medicine, Gachon University Gil Medical Center, Incheon; ${ }^{7}$ Division of Pulmonary and Critical Care Medicine, Department of Internal Medicine, Konkuk University Medical Center, Seoul; ${ }^{8}$ Division of Pulmonary, Allergy and Critical Care Medicine, Department of Internal Medicine, Hallym University Sacred Heart Hospital, Anyang; ${ }^{9}$ Department of Pulmonary and Critical Care Medicine, Asan Medical Center, University of Ulsan College of Medicine, Seoul, Korea
\end{abstract}

Received: April 1, 2019 Revised : June 17, 2019 Accepted: July 1, 2019
Background/Aims: Despite increasing awareness of the burden of chronic obstructive pulmonary disease (COPD) in women, knowledge regarding gender differences in COPD outcomes is limited. Therefore, we aimed to evaluate whether COPD outcomes, including exacerbations, lung function, and symptoms differ by gender.

Methods: We recruited patients with COPD from two Korean multicenter prospective cohorts. After propensity score matching, the main outcome, the incidence of moderate or severe exacerbations was analyzed using a negative binomial regression model. We also assessed changes in lung function and symptom scores including the St. George's respiratory questionnaire for COPD (SGRQ-C), COPD assessment test (CAT), and the modified Medical Research Council (mMRC) dyspnea score.

Results: After propensity score matching, 74 women and 74 men with COPD were included. The incidence rates of exacerbations in women and men were not significantly different (incidence rate ratio, 1.49; 95\% confidence interval [CI], o.88 to 2.54). There was no significant difference in the incidence rates adjusted for medication possession ratios of long-acting muscarinic antagonists, long-acting $\beta$-agonists, and inhaled corticosteroids during the follow-up period (incidence rate ratio, 1.47; 95\% CI, 0.86 to 2.52). Rates of decline in post-bronchodilator forced expiratory volume in 1 second and forced vital capacity did not differ between women and men during 48 months of follow-up. The changes in scores on the SGRQ-C, CAT, and mMRC Questionnaire in women were also similar to those in men.

Conclusions: We observed no gender differences in the rate of exacerbations of COPD in a prospective longitudinal study. Further studies are needed to confirm these findings in the general COPD population.

Keywords: Chronic obstructive pulmonary disease; Women; Men; Prospective studies

Correspondence to Chang-Hoon Lee, M.D.

Division of Pulmonary and Critical Care Medicine, Department of Internal Medicine, Seoul National University Hospital, 101 Daehak-ro, Jongno-gu, Seoul, 03080, Korea Tel: +82-2-2072-4743, Fax:+82-2-762-9662, E-mail: kauri67o@empal.com https://orcid.org/0000-0001-9960-1524 


\section{INTRODUCTION}

Since chronic obstructive pulmonary disease (COPD) was considered a disease of elderly male smokers, women have been less likely than men to be diagnosed with COPD [1]. However, as the prevalence of smoking in women has steadily increased over time, COPD is being diagnosed more frequently in women than in men especially in high-income countries [2-4]. The prevalence and the morbidity and mortality rates of COPD have steadily increased in women during the past decades [5]. As the COPD mortality rate in men is steeply decreasing, the gender difference in COPD mortality is narrowing [6].

Despite increasing awareness of the burden of COPD in women, knowledge regarding gender differences in COPD is mainly limited to a pattern of gender-specific characteristics [7]. Women with COPD are more likely to be younger and never-smokers [8-10]. Women are more predisposed to small airway disease, while emphysema is reported less frequently in them [11,12]. Some studies have reported a greater prevalence of dyspnea and worse health-related quality of life in women [8,9,13-16], while others have not $[17,18]$. Comorbidities, including cardiovascular disease, are more frequently associated with COPD in men; osteoporosis, anxiety, and depression, in women $[9,13,19]$.

However, studies investigating gender differences in COPD outcomes, including exacerbations are scarce [7]. Although there were a few post hoc analyses of randomized controlled trials $[8,15,20]$, the rest were cross-sectional or retrospective cohort studies [21,22]. These post hoc analyses reported a higher rate of exacerbations in women than in men. While increased oxidative stress and transforming growth factor $\beta 1$ signaling regulated by female hormones were proposed as mechanisms underlying the greater susceptibility to COPD in women than in men for a given level of cigarette smoke exposure $[23,24]$, it remains unclear if these proposed biological mechanisms can explain any gender differences in COPD outcomes. Moreover, it was demonstrated that patients with COPD enrolled in these clinical trials differed from real-world patients in terms of gender ratio, lung function, quality of life, and exacerbations: they were predominantly male, with a history of exacerbations in the preceding year, and had worse lung function and quality of life when compared with the real-world patient population [25]. We aimed to evaluate whether COPD outcomes including exacerbations, lung function, and symptoms differ by gender in a prospective, longitudinal study.

\section{METHODS}

\section{Patients}

We recruited participants from two different prospective cohorts in the Republic of Korea: the Korean Obstructive Lung Disease (KOLD) cohort, recruiting participants at 17 centers since 2005 [26], and the Korean COPD Subgroup Study (KOCOSS; NCTo2800499) cohort, recruiting participants at 45 centers since 2011 [27]. Participants were eligible for the present study if they were 40 years or older, had post-bronchodilator forced expiratory volume in 1 second $\left(\mathrm{FEV}_{1}\right) /$ forced vital capacity (FVC) less than 0.7 , and had a tobacco smoking history of at least 10 pack-years. Participants with a tobacco smoking history of less than 10 pack-years were also included if they had a biomass fuel (firewood or briquette) exposure history of at least 10 years. Participants who were followed up for less than 6 months and those who did not complete baseline information were excluded. The present study was approved by the Institutional Review Board of the Seoul National University Hospital (H-1706-079-859). All participants provided written informed consent and the study was conducted in accordance with the tenets of the Declaration of Helsinki.

\section{Measurement of variables and outcomes}

The following clinical data were collected from each cohort: age, gender, body mass index, smoking status, a history of biomass fuel (firewood or briquette) exposure, a history of exacerbations during the previous year, and comorbidities. Biomass fuel exposure was determined by the same questions in both cohorts: "Have you ever burned firewood for cooking or heating for over a year in your lifetime? If yes, how many years have you burned firewood as fuel?" and "Have you ever used briquettes for cooking or heating for over a year in your lifetime? If yes, how many years have you used briquettes as fuel?"

After a baseline visit, patients were followed up every 3 months (the KOLD cohort) or 6 months (the KOCOSS 
cohort) with detailed interviews. At each visit, all exacerbations were recorded by a study physician or trained nurse. An exacerbation was defined as moderate when any worsening of respiratory symptoms led to treatment with systemic corticosteroids, antibiotics, or both, and severe if it led to a hospital admission or an emergency department visits $[28,29]$.

Participants underwent pre- and post-bronchodilator spirometry at baseline and at least annually thereafter. Symptom scores including the St. George's respiratory questionnaire for COPD (SGRQ-C) [30], COPD assessment test (CAT) [31], and modified Medical Research Council (mMRC) Questionnaire [32] were recorded at baseline and at least 6-month intervals. The use of drugs, including long-acting muscarinic antagonist (LAMA), long-acting $\beta$-agonist (LABA), and inhaled corticosteroid (ICS) at enrollment and medication possession ratios (MPRs) of those drugs during the follow-up period were also recorded.

The main outcome was the incidence of moderate or severe COPD exacerbations. We also assessed the decline in lung function and symptom scores, including the SGRQ-C, CAT, and mMRC Questionnaire.

\section{Statistical analysis}

Clinical characteristics were compared between women and men, using the independent samples $t$ test for continuous variables. For categorical variables, either the chi-square test or Fisher's exact test were used for comparison.

Propensity score matching was applied to compare women with men with similar characteristics. Multivariable logistic regression was used to compute the propensity score for women using the following baseline covariates; age, body mass index, smoking status (never-smoker vs. former smoker vs. current smoker), smoking history (pack-years), biomass fuel exposure history ( $<10$ years vs. $\geq 10$ years vs. unknown), SGRQ-C total score ( $<25$ vs. $\geq 25$ vs. unknown), CAT score ( $<10$ vs. $\geq 10$ vs. unknown), mMRC dyspnea score ( $<2$ vs. $\geq 2$ vs. unknown), exacerbation history during the previous year (yes vs. no vs. unknown), blood eosinophil ( $\leq 5 \%$ vs. $>5 \%$ vs. unknown), post-bronchodilator $\mathrm{FEV}_{1}$ (\% predicted), post-bronchodilator FVC (\% predicted), bronchodilator response of $\mathrm{FEV}_{1}(\%)$, and use of LAMA, LABA, or ICS at enrollment. Following this, 1:1 matching was conducted by the nearest neighbor method within a caliper of 0.25 of the propensity score. The incidence rates of moderate or severe exacerbations were compared using the negative binomial regression model. The time to the first moderate or severe exacerbation was analyzed using the Kaplan-Meier method. Changes in post-bronchodilator $\mathrm{FEV}_{1}$ and FVC and symptom scores were analyzed with the use of random-slope and random-intercept mixed linear regression.

A $p$ values less than 0.05 were considered significant. Statistical analyses were performed using the Stata statistical software version 14.2 (StataCorp LP, College Station, TX, USA).

\section{RESULTS}

Of the 2022 patients with COPD enrolled in the two cohorts, 618 were excluded (Fig. 1). A total of 89 women and 1,315 men with COPD were analyzed. Table 1 summarizes their clinical characteristics at baseline. Prior to matching, women were observed as more likely to be never-smokers $(49.4 \%$ vs. $1.7 \%, p<0.001)$ and have biomass fuel exposure history of greater than or equal to 10 years $(69.7 \%$ vs. $41.0 \%, p<0.001)$. Diabetes mellitus was less prevalent in women (7.0\% vs. $16.0 \%, p=$

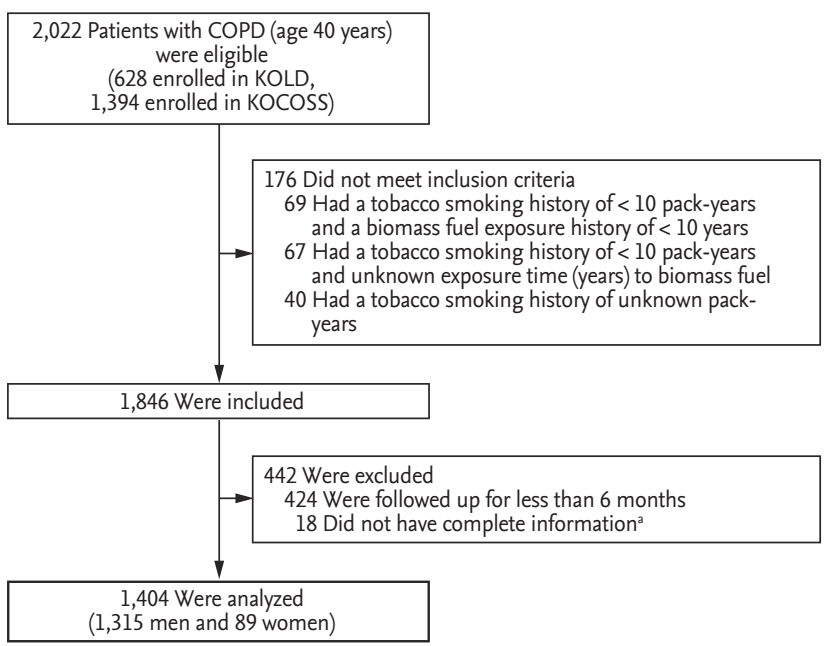

Figure 1. Flowchart of patient selection. COPD, chronic obstructive pulmonary disease; KOCOSS, Korean COPD Subgroup Study; KOLD, Korean Obstructive Lung Disease. ${ }^{\mathrm{a}} \%$ predicted post-bronchodilator forced expiratory volume in 1 second and forced vital capacity, and body mass index. 
Table 1. Baseline characteristics of the study patients before and after propensity score matching

\begin{tabular}{|c|c|c|c|c|c|c|}
\hline \multirow[b]{2}{*}{ Characteristic } & \multicolumn{3}{|c|}{ Before propensity score matching } & \multicolumn{3}{|c|}{ After propensity score matching } \\
\hline & $\begin{array}{c}\text { Men } \\
(n=1,315)\end{array}$ & $\begin{array}{l}\text { Women } \\
(\mathrm{n}=89)\end{array}$ & $p$ value & $\begin{array}{c}\text { Men } \\
(\mathrm{n}=74)\end{array}$ & $\begin{array}{l}\text { Women } \\
(\mathrm{n}=74)\end{array}$ & $p$ value \\
\hline Age, yr & $68.5 \pm 7.5$ & $69.2 \pm 7.4$ & 0.394 & $68.3 \pm 8.1$ & $68.6 \pm 7.6$ & 0.794 \\
\hline $\mathrm{BMI}, \mathrm{kg} / \mathrm{m}^{2}$ & $22.9 \pm 3.3$ & $23.7 \pm 3.7$ & 0.016 & $24.0 \pm 3.2$ & $23.5 \pm 3.7$ & 0.334 \\
\hline Smoking & & & $<0.001$ & & & 0.268 \\
\hline Never-smoker & $22(1.7)$ & $44(49 \cdot 4)$ & & $22(29.7)$ & $29(39.2)$ & \\
\hline Former smoker & $921(70.0)$ & $24(27.0)$ & & $22(29.7)$ & $24(32.4)$ & \\
\hline Current s moker & $372(28.3)$ & $21(23.6)$ & & $30(40.5)$ & $21(28.4)$ & \\
\hline Smoking, pack-years & $44.7 \pm 25.8$ & $15.7 \pm 20.9$ & $<0.001$ & $20.7 \pm 21.0$ & $18.9 \pm 21.6$ & 0.615 \\
\hline Exposure to biomass fuel, yr & & & $<0.001$ & & & 0.410 \\
\hline$<10$ & $423(32.2)$ & $9(10.1)$ & & $12(16.2)$ & $9(12.2)$ & \\
\hline$\geq 10$ & $539(41.0)$ & $62(69.7)$ & & $39(52.7)$ & $47(63.5)$ & \\
\hline Unknown & $353(26.8)$ & $18(20.2)$ & & $23(31.1)$ & $18(24 \cdot 3)$ & \\
\hline Exacerbations during the previous year & & & 0.528 & & & $>0.999$ \\
\hline No & $954(72.6)$ & $64(71.9)$ & & $55(74 \cdot 3)$ & $54(73.0)$ & \\
\hline Yes & $321(24 \cdot 4)$ & $24(27.0)$ & & $18(24 \cdot 3)$ & $19(25 \cdot 7)$ & \\
\hline Unknown & $40(3.0)$ & $1(1.1)$ & & $1(1.4)$ & $1(1.4)$ & \\
\hline SGRQ-C total score ${ }^{a}$ & $34.7 \pm 19.0$ & $37.5 \pm 19.8$ & 0.188 & $35.6 \pm 20.3$ & $35.1 \pm 18.4$ & 0.892 \\
\hline SGRQ-C total score & & & 0.525 & & & 0.929 \\
\hline$<25$ & $462(35 \cdot 1)$ & $26(29.2)$ & & $25(33.8)$ & $24(32.4)$ & \\
\hline$\geq 25$ & $798(60.7)$ & $59(66.3)$ & & $44(59 \cdot 5)$ & $46(62.2)$ & \\
\hline Unknown & $55(4.2)$ & $4(4 \cdot 5)$ & & $5(6.8)$ & $4(5 \cdot 4)$ & \\
\hline CAT score ${ }^{\mathrm{b}}$ & $15.1 \pm 8.0$ & $16.3 \pm 8.9$ & 0.210 & $15.6 \pm 8.6$ & $15 \cdot 3 \pm 7.8$ & 0.833 \\
\hline CAT score & & & 0.827 & & & 0.874 \\
\hline$<10$ & $279(21.2)$ & $20(22.5)$ & & $14(18.9)$ & $16(21.6)$ & \\
\hline$\geq 10$ & $767(58.3)$ & $49(55 \cdot 1)$ & & $43(58.1)$ & $40(54.1)$ & \\
\hline Unknown & $269(20.5)$ & $89(22.5)$ & & $17(23.0)$ & $18(24 \cdot 3)$ & \\
\hline mMRC dyspnea score ${ }^{c}$ & $1.5 \pm 1.0$ & $1.6 \pm 0.9$ & 0.494 & $1.6 \pm 1.0$ & $1.5 \pm 0.9$ & 0.856 \\
\hline mMRC dyspnea score & & & 0.726 & & & $>0.999$ \\
\hline$<2$ & $706(53 \cdot 7)$ & $44(49 \cdot 4)$ & & $38(51.4)$ & $38(51.4)$ & \\
\hline$\geq 2$ & $564(42.9)$ & $42(47.2)$ & & $33(44.6)$ & $33(44.6)$ & \\
\hline Unknown & $45(3 \cdot 4)$ & $3(3.4)$ & & $3(4.1)$ & $3(4.1)$ & \\
\hline Post-bronchodilator $\mathrm{FEV}_{1}, \%$ predicted & $58.8 \pm 17.9$ & $65.8 \pm 20.7$ & 0.002 & $60.8 \pm 19.0$ & $61.9 \pm 16.9$ & 0.700 \\
\hline Post-bronchodilator FVC, \% predicted & $85.6 \pm 18.0$ & $89.4 \pm 18.5$ & 0.054 & $87.5 \pm 19.9$ & $86.6 \pm 17.2$ & 0.773 \\
\hline Post-bronchodilator $\mathrm{FEV}_{1} / \mathrm{FVC}$ \% & $48.4 \pm 11.4$ & $53.6 \pm 10.9$ & $<0.001$ & $49.0 \pm 11.8$ & $52.6 \pm 10.7$ & 0.053 \\
\hline Bronchodilator response $\left(\mathrm{FEV}_{1}\right), \%$ & $7 \cdot 9 \pm 11.8$ & $7.1 \pm 13.6$ & 0.618 & $7.0 \pm 10.5$ & $7 \cdot 7 \pm 14.0$ & 0.749 \\
\hline Blood eosinophil, $/ \mu \mathrm{L}^{\mathrm{d}}$ & $266 \pm 314$ & $206 \pm 208$ & 0.022 & $208 \pm 192$ & $225 \pm 224$ & 0.671 \\
\hline Blood eosinophil, \% ${ }^{\mathrm{e}}$ & $3.6 \pm 3.7$ & $2.8 \pm 2.5$ & 0.018 & $2.8 \pm 2.5$ & $3.1 \pm 2.7$ & 0.564 \\
\hline Blood eosinophil & & & 0.133 & & & 0.663 \\
\hline$\leq 5 \%$ & $842(64.0)$ & $66(74.2)$ & & $50(67.6)$ & $52(70.3)$ & \\
\hline$>5 \%$ & $217(16.5)$ & $9(10.1)$ & & $7(9.5)$ & $9(12.2)$ & \\
\hline Unknown & $256(19 \cdot 5)$ & $14(15 \cdot 7)$ & & $17(23.0)$ & $13(17.6)$ & \\
\hline
\end{tabular}


Table 1. Continued

\begin{tabular}{|c|c|c|c|c|c|c|}
\hline \multirow[b]{2}{*}{ Characteristic } & \multicolumn{3}{|c|}{ Before propensity score matching } & \multicolumn{3}{|c|}{ After propensity score matching } \\
\hline & $\begin{array}{c}\text { Men } \\
(\mathrm{n}=1,315)\end{array}$ & $\begin{array}{l}\text { Women } \\
(\mathrm{n}=89)\end{array}$ & $p$ value & $\begin{array}{c}\text { Men } \\
(\mathrm{n}=74)\end{array}$ & $\begin{array}{l}\text { Women } \\
(\mathrm{n}=74)\end{array}$ & $p$ value \\
\hline Use of LAMA at enrollment & $701(53 \cdot 3)$ & $35(39 \cdot 3)$ & 0.011 & $32(43.2)$ & $32(43.2)$ & $>0.999$ \\
\hline Use of LABA at enrollment & $702(53 \cdot 4)$ & $46(51.7)$ & 0.756 & $49(66.2)$ & $38(51.4)$ & 0.066 \\
\hline Use of ICS at enrollment & $554(42.1)$ & $42(47.2)$ & 0.350 & $42(56.8)$ & $34(46.0)$ & 0.188 \\
\hline
\end{tabular}

Values are presented as mean $\pm \mathrm{SD}$ or number (\%).

BMI, body mass index; SGRQ-C, St. George's Respiratory Questionnaire for COPD; CAT, COPD assessment test; COPD, chronic obstructive pulmonary disease; mMRC, modified Medical Research Council; $\mathrm{FEV}_{1}$, forced expiratory volume in 1 second; FVC, forced vital capacity; LAMA, long-acting muscarinic antagonist; LABA, long-acting $\beta$-agonist; ICS, inhaled corticosteroid.

${ }^{a}$ Data are for 1,260 men and 85 women before propensity score matching, and 69 men and 70 women after propensity score matching.

${ }^{\mathrm{b}}$ Data are for 1,046 men and 69 women before propensity score matching, and 57 men and 56 women after propensity score matching.

${ }^{\mathrm{c}}$ Data are for 1,270 men and 86 women before propensity score matching, and 71 men and 71 women after propensity score matching.

${ }^{\mathrm{d}}$ Data are for 1,055 men and 75 women before propensity score matching, and 57 men and 61 women after propensity score matching.

${ }^{\mathrm{e}}$ Data are for 1,059 men and 75 women before propensity score matching, and 57 men and 61 women after propensity score matching

Table 2. Incidence rates of moderate or severe exacerbations by gender

\begin{tabular}{|c|c|c|c|c|c|c|c|c|c|c|c|c|}
\hline \multirow{3}{*}{ Variable } & \multicolumn{6}{|c|}{ Before propensity score matching } & \multicolumn{6}{|c|}{ After propensity score matching } \\
\hline & \multicolumn{2}{|c|}{$\operatorname{Men}(n=1,315)$} & \multicolumn{2}{|c|}{ Women $(\mathrm{n}=89)$} & \multirow{2}{*}{$\begin{array}{c}\text { IRR }^{\mathrm{a}} \\
(95 \% \mathrm{CI})\end{array}$} & \multirow{2}{*}{$\begin{array}{c}\mathrm{IRR}^{\mathrm{b}} \\
(95 \% \mathrm{CI})\end{array}$} & \multicolumn{2}{|c|}{$\operatorname{Men}(n=74)$} & \multicolumn{2}{|c|}{ Women $(\mathrm{n}=74)$} & \multirow{2}{*}{$\begin{array}{c}\operatorname{IRR}^{\mathrm{a}} \\
(95 \% \mathrm{CI})\end{array}$} & \multirow{2}{*}{$\begin{array}{c}\operatorname{IRR}^{\mathrm{c}} \\
(95 \% \mathrm{CI})\end{array}$} \\
\hline & No. (\%) & $\mathrm{IR}^{\mathrm{a}}$ & No. (\%) & $\mathrm{IR}^{\mathrm{a}}$ & & & No. (\%) & $\mathrm{IR}^{\mathrm{a}}$ & No. (\%) & $\mathrm{IR}^{\mathrm{a}}$ & & \\
\hline Exacerbations & $574(43.7)$ & 0.65 & $38(42.7)$ & 0.62 & $\begin{array}{c}0.95 \\
(0.66-1.38)\end{array}$ & $\begin{array}{c}1.12 \\
(0.74-1.71)\end{array}$ & $32(43.2)$ & 0.44 & $33(44.6)$ & 0.66 & $\begin{array}{c}1.49 \\
(0.88-2.54)\end{array}$ & $\begin{array}{c}1.47 \\
(0.86-2.52)\end{array}$ \\
\hline
\end{tabular}

IR, incidence rate (per patient-year); IRR, incidence rate ratio; CI, confidence interval.

${ }^{\text {a}}$ Unadjusted.

${ }^{\mathrm{b}}$ Adjusted for age, body mass index, smoking status (never-smoker vs. former smoker vs. current smoker), exacerbation history during the previous year (yes vs. no vs. unknown), St. George's Respiratory Questionnaire for chronic obstructive pulmonary disease (COPD) total score (<25 vs. $\geq 25$ ), and \% predicted post-bronchodilator $\mathrm{FEV}_{1}$ (as continuous variables).

${ }^{\mathrm{c}}$ Adjusted for medication possession ratios of long-acting muscarinic antagonists, long-acting $\beta$-agonists, and inhaled corticosteroids during the follow-up period as continuous variables.

$0.025)$, whereas gastroesophageal reflux disease $(20.0 \%$ vs. $12.6 \%, p=0.074$ ) and osteoporosis (25.0\% vs. $4.9 \%$, $p<0.001)$ were more prevalent. The mean SGRQ-C total scores $(37.5 \pm 19.8$ vs. $34.7 \pm 19.0, p=0.188)$, mean CAT scores $(16.3 \pm 8.9$ vs. $15.1 \pm 8.0, p=0.210)$, and mean mMRC dyspnea scores ( $1.6 \pm 0.9$ vs. $1.5 \pm 1.0, p=0.494)$ were similar in women and men. Compared with men, post-bronchodilator $\mathrm{FEV}_{1}$ was higher in women $(65.8 \% \pm$ $20.7 \%$ vs. $58.8 \% \pm 17.9 \%$ predicted, $p=0.002)$. Less wom en than men tended to use LAMA at enrollment $(39.3 \%$ vs. 53.3\%, $p=0.011$ ). After matching (Supplementary Fig. 1), 74 women and 74 men were followed up for a mean period of 2.7 and 3.1 years, respectively. Clinical characteristics of the matched pairs of women and men were comparable (Table 1). The mean MPRs of LAMA (41.7\% $\pm 41.7 \%$ vs. $47.7 \% \pm 41.6 \%, p=0.382)$, LABA ( $55.0 \pm 38.8$ vs. $63.1 \pm 39.4 \%, p=0.209)$, and ICS (44.9\% $\pm 40.0 \%$ vs. $54.7 \%$ $\pm 41.3 \%, p=0.144)$ during the follow-up period were not significantly different between women and men.

In the propensity score-matched cohort, 33 (44.6\%) 


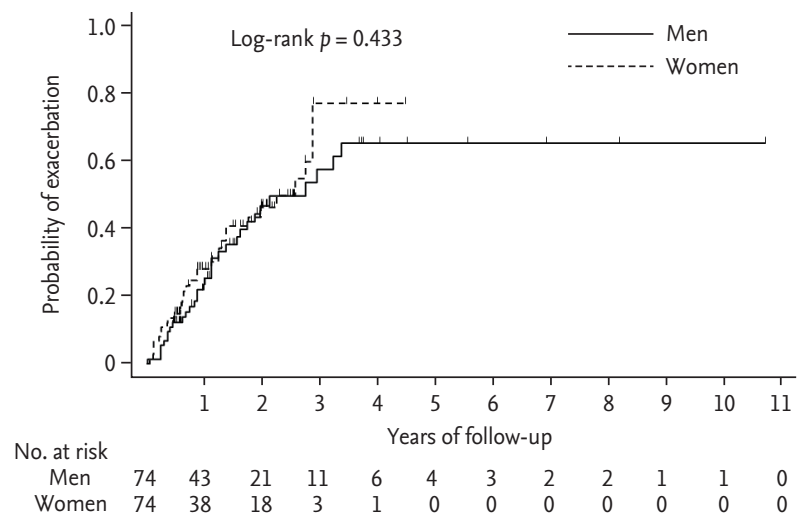

Figure 2. Kaplan-Meier curves of the time to the first moderate or severe exacerbation in the propensity score-matched cohort.

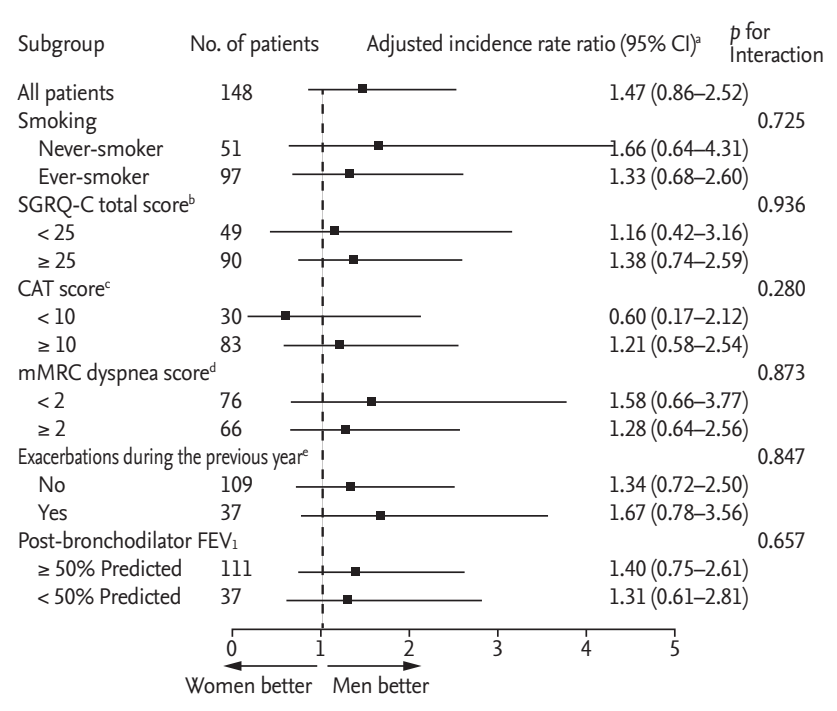

Figure 3. Subgroup analyses of moderate or severe exacerbations in the propensity score-matched cohort. CI, confidence interval; SGRQ-C, St. George's Respiratory Questionnaire for COPD; CAT, chronic obstructive pulmonary disease assessment test; mMRC, modified Medical Research Council; $\mathrm{FEV}_{1}$, forced expiratory volume in 1 second. ${ }^{\mathrm{a}}$ Adjusted for medication possession ratios of long-acting muscarinic antagonist, long-acting $\beta$-agonist, and inhaled corticosteroids during the follow-up period as continuous variables. ${ }^{\text {b Us- }}$ able data regarding the SGRQ-C total score at baseline were missing for nine patients. ${ }^{C}$ Usable data regarding the CAT score at baseline were missing for 35 patients. ${ }^{\mathrm{d}}$ Usable data regarding the $\mathrm{mMRC}$ dyspnea score at baseline were missing for six patients. ${ }^{\mathrm{e}}$ Usable data regarding the exacerbation history during the previous year were missing for two patients at baseline. women experienced 184 episodes of moderate or severe exacerbation, whereas 32 (43.2\%) men experienced 107 such episodes during the follow-up period. The incidence rates of exacerbations in women and men were not significantly different (incidence rate ratio, 1.49; 95\% confidence interval [CI], 0.88 to 2.54 ) (Table 2). The difference in the incidence rates were not significant even after adjustment for MPRs of LAMA, LABA, and ICS during the follow-up period (incidence rate ratio, 1.47; 95\% CI, 0.86 to 2.52). Furthermore, the time to the first moderate or severe exacerbation did not differ significantly by gender (log-rank $p=0.433$ ) (Fig. 2). Similar results were observed in subgroup analyses of rates of moderate or severe exacerbation (Fig. 3).

In the propensity score-matched cohort, rates of decline in post-bronchodilator $\mathrm{FEV}_{1}$ and FVC were not different in women and men during 48 months of follow-up (Fig. $4 \mathrm{~A}$ and $4 \mathrm{~B}$ ). The changes in scores on the SGRQ-C, CAT, and mMRC Questionnaire in women were similar to those in men in the follow-up period (Fig. $4 \mathrm{C}-4 \mathrm{E}$ ).

\section{DISCUSSION}

We conducted a propensity score-matched analysis in a prospective cohort of patients with COPD to evaluate whether gender has an impact on COPD outcomes including exacerbations, lung function, and symptoms. Our study showed that the incidence rates of exacerbations were not significantly different between women and men, nor were there any gender differences in symptoms and lung function changes during the follow-up period.

There are post hoc analyses of randomized controlled trials reporting that women with COPD experience disease exacerbations more than men with COPD. In a post hoc analysis of the Towards a Revolution in COPD Health (TORCH) trial [33], the time to the first moderate or severe exacerbation was shorter and the rate of exacerbation was reported to be $25 \%$ (95\% CI, $16 \%$ to $34 \%)$ higher in women than in men although rates of exacerbations requiring hospitalization were similar in both genders [8]. Data from the Understanding Potential Long-Term Impacts on Function with Tiotropium (UPLIFT) [34] and the Prevention of Exacerbations with 
A
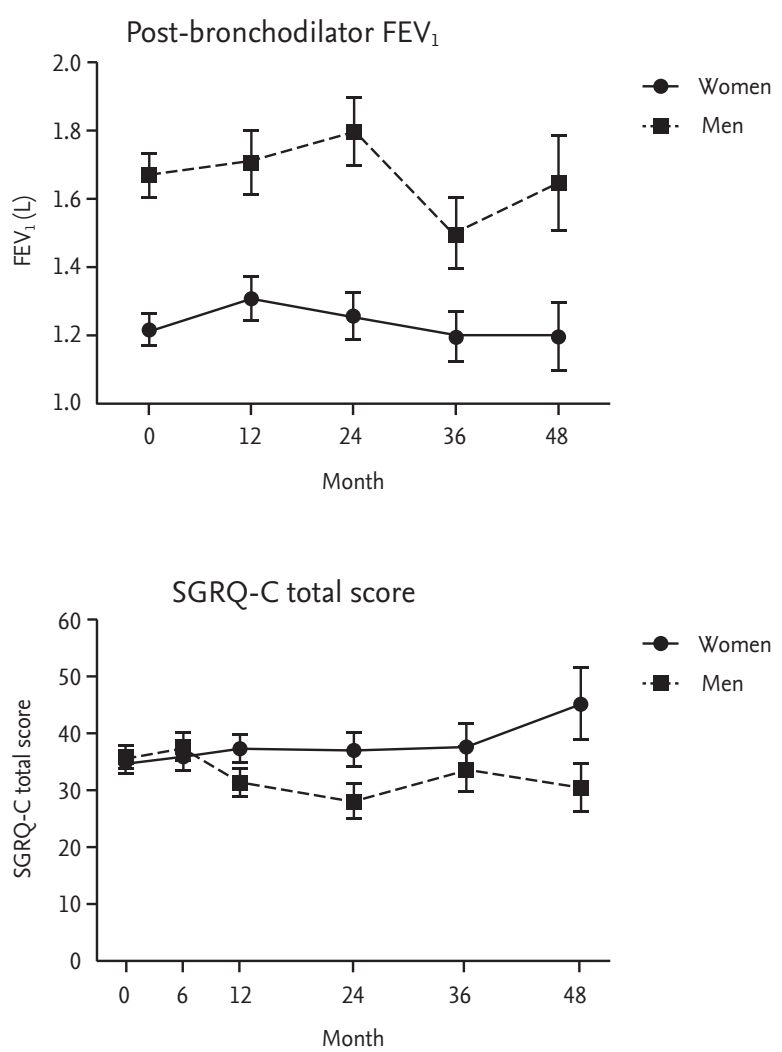

C

$\mathbf{E}$

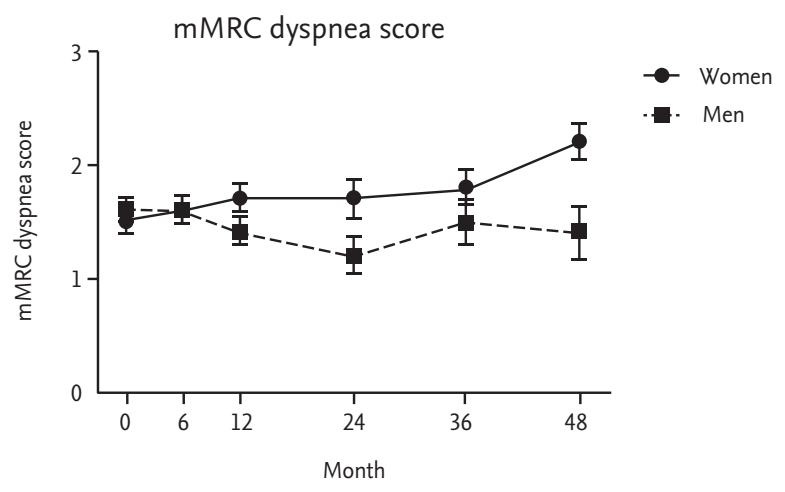

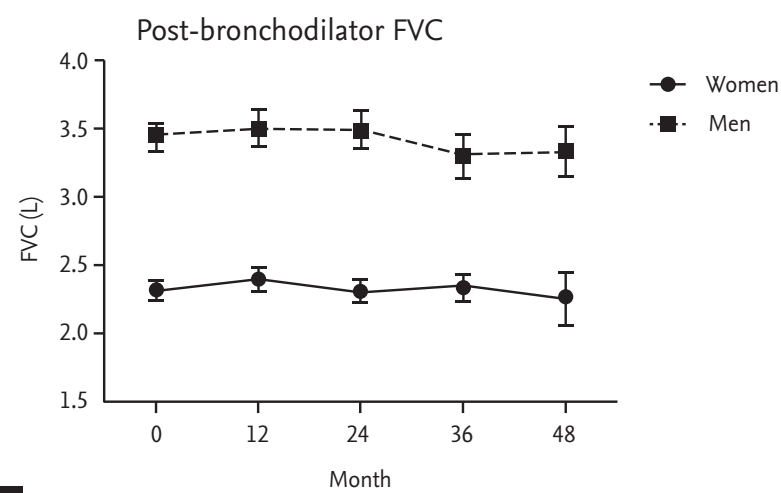

B

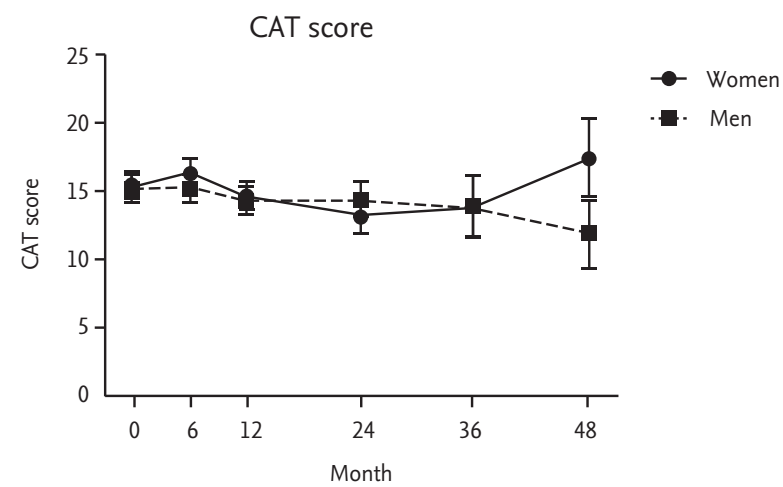

D

Figure 4. Mean post-bronchodilator forced expiratory volume in 1 second $\left(\mathrm{FEV}_{1}\right)$ and forced vital capacity (FVC), and symptom scores over 48 months. (A) Post-bronchodilator $\mathrm{FEV}_{1}$. A p values were 0.764 at 12 months, 0.680 at 24 months, 0.595 at 36 months, 0.809 at 48 months. (B) Post-bronchodilator FVC. A p values were 0.981 at 12 months, 0.854 at 24 months, 0.574 at 36 months, 0.871 at 48 months. (C) St. George's Respiratory Questionnaire for COPD (SGRQ-C) total score. A p values were 0.953 at 6 months, 0.117 at 12 months, 0.222 at 24 months, 0.706 at 36 months, 0.522 at 48 months. (D) COPD assessment test (CAT) score. A p values were 0.365 at 6 months, 0.750 at 12 months, 0.965 at 24 months, 0.204 at 36 months, 0.156 at 48 months. (E) Modified Medical Research Council (mMRC) dyspnea score. A p values were 0.832 at 6 months, 0.057 at 12 months, 0.176 at 24 months, 0.804 at 36 months, 0.563 at 48 months. COPD, chronic obstructive pulmonary disease.

Tiotropium in COPD (POET-COPD) trials [35] also reported that women had higher incidence rates of exacerbation than men $[15,20]$. Although the results of these analyses on exacerbations in women and men were consistent, they may not represent the general COPD population. A validation study of six large pharmaceutically-sponsored COPD studies including TORCH, UPLIFT, and POET-COPD demonstrated that patients 
with COPD in these studies differed from patients with COPD routinely seen in primary care set-ups in Europe in terms of gender, exacerbations, lung function, and quality of life: they were predominantly male with a history of exacerbations in the preceding year and showed worse lung function and quality of life scores [25]. Patients with COPD were considered eligible for these trials if they had a history of previous exacerbation and/or moderate or severe airflow limitation [33-35]. As a result, the majority ( $58 \%$ to $83 \%$ ) of patients with COPD in primary care would not qualify as a candidate for inclusion in these trials [25].

In addition, these trials included smokers only. Although tobacco smoking is the most well-studied risk factor for COPD, epidemiologic studies have demonstrated that biomass fuel exposure is under-recognized as a risk factor for COPD [36]. Furthermore, in the randomized controlled trials, although the factors under consideration were balanced between treatment groups by randomization, it cannot be said that they were balanced between genders. In the TORCH trial, women subjects tended to present with worse mMRC dyspnea scores at baseline (20\% with 4 or 5 vs. $18 \%, p<0.001$ ) and had more exacerbations in the year before the study (59\% vs. $56 \%, p=0.113$ ) than did men [8]. It is difficult to conclude, however, that these differences in COPD exacerbation are based on gender, without considering the differences in symptoms and the prior history of exacerbation.

Our prospective cohort study recruited participants from the actual clinical setting and was not restricted to including patients with COPD with exposure to tobacco smoke only; we also considered exposure to biomass fuels. Additionally, we attempted to reduce the effects of confounding by applying propensity score matching with covariates including the exposure history to tobacco smoke and biomass fuels, symptom scores, and the history of exacerbations in the preceding year. To our knowledge, our study is the first prospective, gender-specific observational study on moderate or severe COPD exacerbations. Although the Danish longitudinal population study reported gender difference and risk of hospitalization for COPD in 1997, hospitalization was not specified as exacerbations [37]. Available covariates were balanced between women and men in our study. After matching, the rate of exacerbations was slightly but not significantly higher in women than in men.

The prevalence of cigarette smoking among women in Asia is typically lower than that in Western countries. Prior to matching, approximately half of women were never-smokers and less than a quarter were current smokers in the present study (Table 1). After matching, $28.4 \%$ of women and $40.5 \%$ of men were current smokers, and the average pack-years of smoking were 18.9 and 20.7 in women and men, respectively. In the TORCH and UPLIFT trials, the proportion of current smokers in women (34\% to $49 \%$ ) was higher than that in men $(26 \%$ to $41 \%)$, and the average pack-years of smoking were approximately 40 and 50 in women and men, respectively. Differences in exposures to tobacco smoke and biomass fuels may lead to a difference in rates of COPD exacerbations.

Our study has several limitations, including its observational design. The main limitation is the small number of women with COPD, which may have resulted in insufficient power to detect the differences between women and men. In addition, the introduction of inhaled therapy and choice of medications by physicians could have been gender-biased. Thus, we applied propensity score-matched analysis with available covariates including the use of LAMA, LABA, and ICS at enrollment, and the incidence rate ratio of exacerbations was adjusted for MPRs of drugs during the follow-up period.

In conclusion, there has been limited knowledge regarding the interplay of gender and disease outcomes in patients with COPD. We observed that gender made no difference in the rates of exacerbations in a real-world prospective observational study. It remains to be determined if this holds true in the general COPD population.

\section{KEY MESSAGE}

1. There has been limited knowledge regarding the interplay of gender and disease outcomes in patients with of chronic obstructive pulmonary disease (COPD).

2. We observed no gender differences in the rate of exacerbations of COPD in a prospective longitudinal study. 


\section{Conflict of interest}

No potential conflict of interest relevant to this article was reported.

\section{Acknowledgments}

This study included participants from two Korean cohorts, the Korean Obstructive Lung Disease (KOLD) and Korean Chronic Obstructive Pulmonary Disease Subgroup Study (KOCOSS). KOLD was built with the support of a grant of the Korea Healthcare Technology R\&D Project, Ministry for Health and Welfare, Republic of Korea (A102065). KOCOSS was supported by a fund by Research of Korea Centers for Disease Control and Prevention (2016ER670102 \& 2018ER670100).

\section{REFERENCES}

1. Chapman KR, Tashkin DP, Pye DJ. Gender bias in the diagnosis of COPD. Chest 2001;119:1691-1695.

2. Schirnhofer L, Lamprecht B, Vollmer WM, et al. COPD prevalence in Salzburg, Austria: results from the Burden of Obstructive Lung Disease (BOLD) Study. Chest 2007;131:29-36.

3. Mannino DM, Buist AS. Global burden of COPD: risk factors, prevalence, and future trends. Lancet 2007;370:765773 .

4. Vogelmeier CF, Criner GJ, Martinez FJ, et al. Global strategy for the diagnosis, management, and prevention of chronic obstructive lung disease 2017 report. GOLD executive summary. Am J Respir Crit Care Med 2017;195:557582.

5. Aryal S, Diaz-Guzman E, Mannino DM. COPD and gender differences: an update. Transl Res 2013;162:208-218.

6. Lopez-Campos JL, Ruiz-Ramos M, Soriano JB. Mortality trends in chronic obstructive pulmonary disease in Europe, 1994-2010: a joinpoint regression analysis. Lancet Respir Med 2014;2:54-62.

7. Jenkins CR, Chapman KR, Donohue JF, Roche N, Tsiligianni I, Han MK. Improving the management of COPD in women. Chest 2017;151:686-696.

8. Celli B, Vestbo J, Jenkins CR, et al. Sex differences in mortality and clinical expressions of patients with chronic obstructive pulmonary disease. The TORCH experience. Am J Respir Crit Care Med 2011;183:317-322.

9. Roche N, Deslee G, Caillaud D, et al. Impact of gender on COPD expression in a real-life cohort. Respir Res 2014;15:20.

10. Papaioannou AI, Bania E, Alexopoulos EC, Mitsiki E, Malli F, Gourgoulianis KI. Sex discrepancies in COPD patients and burden of the disease in females: a nationwide study in Greece (Greek Obstructive Lung Disease Epidemiology and health ecoNomics: GOLDEN study). Int J Chron Obstruct Pulmon Dis 2014;9:203-213.

11. Camp PG, Coxson HO, Levy RD, et al. Sex differences in emphysema and airway disease in smokers. Chest 2009;136:1480-1488.

12. Hardin M, Foreman M, Dransfield MT, et al. Sex-specific features of emphysema among current and former smokers with COPD. Eur Respir J 2016;47:104-112.

13. Di Marco F, Verga M, Reggente M, et al. Anxiety and depression in COPD patients: the roles of gender and disease severity. Respir Med 2006;100:1767-1774.

14. Carrasco-Garrido P, de Miguel-Diez J, Rejas-Gutierrez J, et al. Characteristics of chronic obstructive pulmonary disease in Spain from a gender perspective. BMC Pulm Med 2009;9:2.

15. Tashkin D, Celli B, Kesten S, Lystig T, Decramer M. Effect of tiotropium in men and women with COPD: results of the 4-year UPLIFT trial. Respir Med 2010;104:1495-1504.

16. Ferrari R, Tanni SE, Lucheta PA, Faganello MM, do Amaral RA, Godoy I. Gender differences in predictors of health status in patients with COPD. J Bras Pneumol 2010;36:37-43.

17. Skumlien S, Haave E, Morland L, Bjortuft O, Ryg MS. Gender differences in the performance of activities of daily living among patients with chronic obstructive pulmonary disease. Chron Respir Dis 2006;3:141-148.

18. Agusti A, Calverley PM, Celli B, et al. Characterisation of COPD heterogeneity in the ECLIPSE cohort. Respir Res 2010;11:122.

19. Raherison C, Tillie-Leblond I, Prudhomme A, et al. Clinical characteristics and quality of life in women with COPD: an observational study. BMC Womens Health 2014;14:31.

20. Beeh KM, Glaab T, Stowasser S, et al. Characterisation of exacerbation risk and exacerbator phenotypes in the POET-COPD trial. Respir Res 2013;14:116.

21. Patil SP, Krishnan JA, Lechtzin N, Diette GB. In-hospital mortality following acute exacerbations of chronic obstructive pulmonary disease. Arch Intern Med 2003;163:1180-1186. 
22. Kilic H, Kokturk N, Sari G, Cakir M. Do females behave differently in COPD exacerbation? Int J Chron Obstruct Pulmon Dis 2015;10:823-830.

23. Tam A, Churg A, Wright JL, et al. Sex differences in airway remodeling in a mouse model of chronic obstructive pulmonary disease. Am J Respir Crit Care Med 2016;193:825834 .

24. Barnes PJ. Sex differences in chronic obstructive pulmonary disease mechanisms. Am J Respir Crit Care Med 2016;193:813-814.

25. Kruis AL, Stallberg B, Jones RC, et al. Primary care COPD patients compared with large pharmaceutically-sponsored COPD studies: an UNLOCK validation study. PLoS One 2014;9:e90145.

26. Park TS, Lee JS, Seo JB, et al. Study design and outcomes of Korean obstructive lung disease (KOLD) cohort study. Tuberc Respir Dis (Seoul) 2014;76:169-174.

27. Lee JY, Chon GR, Rhee CK, et al. Characteristics of patients with chronic obstructive pulmonary disease at the first visit to a pulmonary medical center in Korea: The KOrea COpd Subgroup Study Team Cohort. J Korean Med Sci 2016;31:553-560.

28. Wedzicha JA, Seemungal TA. COPD exacerbations: defining their cause and prevention. Lancet 2007;370:786-796.

29. Yoon HK, Park YB, Rhee CK, Lee JH, Oh YM. Summary of the chronic obstructive pulmonary disease clinical practice guideline revised in 2014 by the Korean Academy of Tuberculosis and Respiratory Disease. Tuberc Respir Dis
(Seoul) 2017;80:230-240.

30. Jones PW, Quirk FH, Baveystock CM, Littlejohns P. A self-complete measure of health status for chronic airflow limitation: the St. George's Respiratory Questionnaire. Am Rev Respir Dis 1992;145:1321-1327.

31. Jones PW, Harding G, Berry P, Wiklund I, Chen WH, Kline Leidy N. Development and first validation of the COPD assessment test. Eur Respir J 2009;34:648-654.

32. Fletcher C. Standardised questionnaire on respiratory symptoms: a statement prepared and approved by the MRC Committee on the Aetiology of Chronic Bronchitis (MRC breathlessness score). BMJ 1960;2:1665.

33. Calverley PM, Anderson JA, Celli B, et al. Salmeterol and fluticasone propionate and survival in chronic obstructive pulmonary disease. N Engl J Med 2007;356:775-789.

34. Tashkin DP, Celli B, Senn S, et al. A 4-year trial of tiotropium in chronic obstructive pulmonary disease. N Engl J Med 2008;359:1543-1554.

35. Vogelmeier C, Hederer B, Glaab T, et al. Tiotropium versus salmeterol for the prevention of exacerbations of COPD. N Engl J Med 2011;364:1093-1103.

36. Hu G, Zhou Y, Tian J, et al. Risk of COPD from exposure to biomass smoke: a metaanalysis. Chest 2010;138:20-31.

37. Prescott E, Bjerg AM, Andersen PK, Lange P, Vestbo J. Gender difference in smoking effects on lung function and risk of hospitalization for COPD: results from a Danish longitudinal population study. Eur Respir J 1997;10:822-827. 


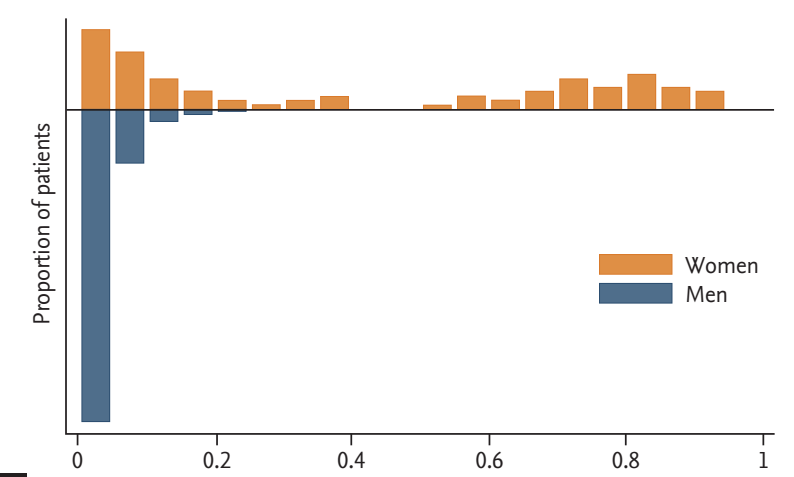

A

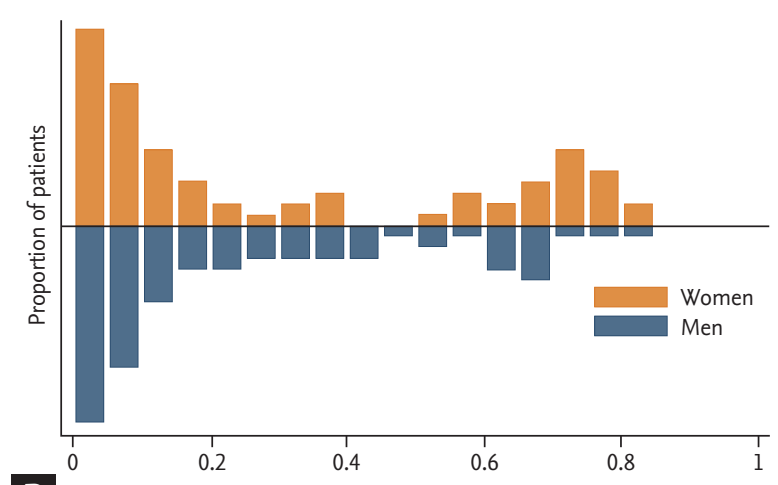

B

Propensity score

Supplementary Figure 1. Histograms of propensity score distribution (TIFF). (A) Before propensity score matching (B) after propensity score matching. 